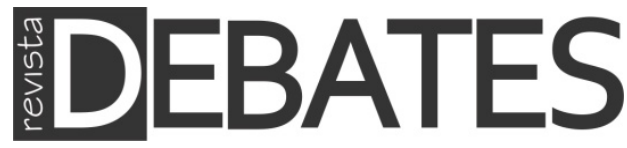

\title{
Satisfação com a democracia entre os brasileiros no cenário recente (2002-2014)
}

\author{
Satisfaction with democracy among Brazilians in the recent scenario \\ (2002-2014)
}

\section{Fabíola Brigante Del Porto}

\section{Resumo}

Com base na análise de resultados do Estudo Eleitoral Brasileiro (ESEB) de 2002 a 2014, e a partir das respostas à pergunta: "De uma maneira geral, o(a) sr.(a) está muito satisfeito(a), satisfeito(a), pouco satisfeito(a) ou nada satisfeito(a) com o funcionamento da democracia no Brasil?" e de seus correlatos atitudinais e socioeconômicos, o artigo descreve a satisfaçáo com a democracia como medida de responsividade do regime aos olhos dos cidadãos e, como tal, como fenômeno multifacetado, que envolve não apenas a avaliação de resultados e conteúdos substantivos das políticas democráticas, como também aspectos institucionais e normativos da democracia representativa. Os resultados sugerem que, embora multifacetado, o fenômeno da satisfaçáo com a democracia no país tem correlatos razoavelmente consistentes através do tempo em termos de avaliação de autoridades e de normas democráticas. Sugerem também que, embora a dimensão econômica seja importante, ela nem sempre é determinante para a satisfação com a democracia no país.

\section{Palavras-chave}

Satisfação com a Democracia; Avaliação de Governo; Responsividade; Instituições Democráticas; Economia.

\begin{abstract}
Based on the Brazilian Electoral Study Data Analysis (ESEB) from 2002 to 2014 and from the answers to the question "On the whole, are you very satisfied, rather satisfied, not very satisfied or not at all satisfied with the way democracy is developing in Brazil?" and its attitudinal and socioeconomic correlates, the article describes the satisfaction with democracy as a measure of responsiveness of the regime to the citizens' view, and, as such, as a multifaceted phenomenon involving not only the evaluation of results and substantial content of the democratic politics, as well as institutional and regulatory aspects of representative democracy. The results suggest that although multifaceted, the phenomenon of satisfaction with democracy in the country has fairly consistent correlates over time in terms of evaluating authorities and democratic norms. They also suggest that, although the economic dimension is important, it is not always determinant to the satisfaction with democracy in the country.
\end{abstract}

\section{Keywords}

Satisfaction with Democracy; Evaluation of Government; Responsiveness; Democratic Institution; Economy. 


\section{Introdução ${ }^{1}$}

Em artigo sobre as bases da avaliação do regime democrático brasileiro, Meneguello (2010) encontra uma dissociação entre a satisfação com a democracia, a atuação das instituiçôes e os resultados de políticas públicas, sugerindo que, para os cidadãos, essas dimensôes não se relacionam diretamente. Segundo a autora, para a necessidade de "[...] um estudo aprofundado sobre o conceito de satisfaçáo com a democracia no país” (MENEGUELLO, 2010, p. 143). Este artigo propóe um estudo exploratório dos fatores que impulsionam a satisfação com a democracia no cenário brasileiro recente, com base na análise longitudinal de medidas de nível individual, obtidas de pesquisas de opinião por amostragem, que fazem parte do Estudo Eleitoral Brasileiro (ESEB) de 2002 a $2014^{2}$. Partindo-se do suposto de que o grau de qualidade da democracia, em termos de procedimentos, conteúdos e resultados, influencia as atitudes e percepçóes acerca do regime democrático (DIAMOND; MORLINO, 2005; RENNÓ et al., 2011; MOISÉS, 2013), procura-se compreender a satisfação com a democracia como medida de responsividade do regime democrático aos olhos dos cidadãos e, nesse sentido, como fenômeno multifacetado que envolve fatores de curto e longo prazo de avaliação ou, nos termos de Easton (1965 e 1975), dimensóes de apoio específico (resposta às autoridades diante da satisfação com desempenho ou resultados percebidos) e difuso (avaliaçáo do que os objetos políticos são ou representam) da democracia.

A análise dos fatores que favorecem a satisfação com a democracia é importante para compreender o cenário de "déficit democrático" que perpassa grande parte das democracias atuais (NORRIS, 2011). Estudos têm mostrado que os

\footnotetext{
${ }^{1}$ Este artigo é parte do projeto de pesquisa "O que sabemos sobre a (in)satisfação com a democracia no Brasil? Orientaçóes avaliativas do regime democrático segundo os brasileiros no período democrático recente (2002-2014)" desenvolvido pela autora com o apoio da Fundação de Amparo à Pesquisa do Estado de São Paulo (Processo Fapesp no 2016/05619-7). Uma versão anterior e parcial deste artigo foi apresentada no XXXIV Congresso Internacional da Associação de Estudos da América Latina (LASA), realizado em Nova York, entre os dias 27 e 30 de maio de 2016. Agradeço à Jana Morgan (University of Tenessee), Dinorah Azpuru (Wichita State University) e Elisa Castro (Purdue University) pelos comentários na ocasião.

${ }^{2} \mathrm{O}$ ESEB é estudo vinculado ao projeto internacional Comparative Study of Electoral Systems (CSES), da Universidade de Michigan (www.cses.org), e, no Brasil, realizado pelo CESOP-UNICAMP sob a coordenação da Profa. Dra. Rachel Meneguello (Departamento de Ciência Política), da Universidade Estadual de Campinas, desde seu início (2002). O ESEB é survey nacional pós-eleitoral, realizado logo após as eleiçóes presidenciais. O questionário aplicado pelo ESEB contém um módulo que é comum a todos os países integrantes do CSES e outro que é desenhado por pesquisadores brasileiros.
} 
insatisfeitos com o regime são menos propensos a aderir à democracia em termos normativos e, quando o fazem, tendem a escolher modelos deficitários de democracia - sem partidos e sem congresso (MOISÉS e CARNEIRO, 2008; SARSFIELD e ECHEGARAY, 2005). A insatisfação política também pode deter o envolvimento político dos cidadãos e comprometer comportamentos de conformidade política necessários ao contrato social subjacente à democracia, como a submissão voluntária à lei (DALTON, 2004; NORRIS, 2011).

Para Norris, a percepção do "déficit democrático" resultaria de processos culturais - como a modernização social e a mobilizaçáo cognitiva - e da racionalidade dos indivíduos, que aumentariam as demandas dos cidadáos por mais e diferentes direitos, assim como os capacitaria a julgar o desempenho do regime não só quanto à sua política substantiva geral, como quanto aos procedimentos institucionais. A esses processos, acrescenta a autora o impacto que a divulgaçáo e o acesso a notícias negativas sobre o desempenho governamental têm sobre as visóes dos cidadáos sobre os governos democráticos (NORRIS, 2011).

Nessa perspectiva, a construção do "déficit democrático" baseia-se na percepção de que o desempenho do regime é falho. Se essa relação parece óbvia, os critérios com os quais os indivíduos avaliam o funcionamento do regime sáo complexos. Para Dalton (2004), nesta avaliação, os cidadãos misturam avaliaçóes dos incumbentes políticos e julgamentos das normas e procedimentos do regime. Este artigo procura contribuir com essa discussão, analisando correlatos e conteúdos da satisfação com a democracia, a partir da análise do cenário brasileiro recente. Para tanto, na próxima seção, o artigo apresenta os aspectos teóricos subjacentes à análise da qualidade da democracia e as percepçóes de legitimidade e efetividade do regime que embasam esta discussão. Em seguida, o cenário brasileiro é apresentado a partir dos resultados do Estudo Eleitoral Brasileiro e as análises estatísticas são realizadas com o intuito de explorar o construto da satisfação com a democracia entre os cidadáos brasileiros no período recente.

\section{Perspectivas teóricas para a análise da satisfação com a democracia no Brasil}

O tema da (in)satisfação com o regime democrático "realmente existente" e está em pauta no país desde o início da experiência brasileira de democracia recente, chamando atenção para o fato de que os cidadáos percebem que a promessa democrática parece não ser realizável (MOISÉS, 1995 e 2010). Não obstante, ainda 
não se produziu uma reflexão sistemática e longitudinal sobre as dimensóes da satisfação com a democracia no país. Os estudos têm se voltado a compreender seus correlatos em termos de avaliaçáo de resultados de políticas democráticas e têm apontado que o nível de satisfação com a democracia é afetado negativamente, entre outros fatores, pela percepção de que a renda é insuficiente, pelas percepçóes e experiências de corrupçáo, de criminalidade e discriminação e pela avaliação da capacidade do governo de gerir a economia (MOISÉS e CARNEIRO, 2008; RENNÓ et al., 2011).

As análises sobre a satisfação com a democracia no país não consideram, porém, o aspecto dinâmico desta e têm como pontos de partida variáveis um pouco distintas. Por exemplo, enquanto Moisés e Carneiro (2008) incluem percepções sobre a economia, Rennó et al. (2011) utilizam recursos que os cidadãos dispóem para cumprir seu papel no processo democrático (por exemplo, o acesso à informaçáo). Essas dimensóes devem ser articuladas para uma compreensão ampliada de como os cidadãos se relacionam com a democracia em termos práticos no país, além da necessidade de considerá-las em termos longitudinais. Em adição, também é necessário considerar: 1. Qual o impacto da avaliação das instituiçôes representativas como instrumentos que fazem a intermediaçáo dos interesses dos cidadáos com o regime, no julgamento que os indivíduos fazem do desempenho da democracia? 2. Como as percepçóes dos cidadáos sobre normas e procedimentos da democracia representativa articulam-se às percepçóes sobre os resultados do regime e sobre a atuação dos governantes do momento na produção de níveis de satisfaçáo com a democracia no Brasil?

Para avançar no entendimento da satisfação com a democracia no país nesse sentido, o artigo segue Meneguello (2010 e 2013) e inclui, no construto da satisfação com o regime, as avaliaçóes das instituiçóes, dos serviços, das políticas públicas, da economia e dos governantes do momento. No entanto, ampliando esse entendimento, agrega à análise as percepçôes dos cidadãos sobre a eficácia de normas e procedimentos da democracia representativa que, segundo Aarts e Thomassen (2008), em diferentes cenários institucionais, afetam a satisfação com a democracia.

Em termos teóricos, essa perspectiva também se baseia em Diamond e Morlino (2005), que avaliam a democracia em termos de sua qualidade quanto a: 1 . Procedimentos (se mecanismos tais como eleiçôes e instituiçôes governamentais sustentam um governo responsivo e de acordo com o primado da lei); 2. Conteúdos (se os cidadáos e associaçóes gozam de amplas liberdades e igualdade política); e 3. Resultados (se as expectativas cidadãs quanto ao cumprimento dos objetivos da 
democracia são satisfeitas). Nessa perspectiva, uma democracia de qualidade configura-se como um sistema de oito dimensôes: cinco procedimentais (primado da lei, participação, competição e accountability vertical e horizontal); duas substantivas (respeito às liberdades civis e políticas e progressiva implantação de maior igualdade política) e uma dimensão de resultados, a responsividade. Essa última relaciona as dimensôes procedimentais às dimensóes substantivas, permitindo mensurar a extensão na qual as açôes governamentais e as políticas democráticas correspondem às expectativas, demandas e preferências dos cidadãos.

O conceito de democracia ${ }^{3}$ como um sistema de qualidades implica que essas oito dimensóes estejam inter-relacionadas e que a melhora em uma dimensão pode ter consequências sobre as outras (DIAMOND e MORLINO, 2005). Enquanto o primado da lei é base para o desenvolvimento das demais dimensôes, a exigência de contínua responsividade dos governos às preferências dos cidadãos também é central para definir uma democracia de qualidade. Para os autores, as percepçóes sobre a responsividade do regime democrático podem ser medidas de modo indireto, perguntando aos indivíduos por sua satisfação com o modo como a democracia trabalha ${ }^{4}$. Sendo a responsividade a dimensão da democracia que articula procedimentos e conteúdos, os cidadãos estarão satisfeitos com o regime não apenas quando perceberem que os governos estabelecem políticas que atendam a suas demandas, mas também quando avaliarem positivamente o próprio processo democrático e os procedimentos associados (POWELL, 2005) 5 .

Norris (2011) retoma essa questáo quando aborda o "déficit democrático". Apontando que a satisfação com a democracia resulta do modo como as pessoas experienciam o processo democrático, a autora detalha que a satisfação com o regime

\footnotetext{
3 A bibliografia sobre as premissas normativas da democracia é bastante extensa e sujeita a interpretações distintas. Ver, por exemplo, Schumpeter (1984), Bobbio (1986), Dahl (1997), O’Donnell (2010).

${ }^{4}$ Mensurar a responsividade é, de fato, tarefa desencorajadora, dada a complexidade dos conceitos e as disputas normativas e teóricas que são postas em questão e a necessidade de estabelecer e verificar a corrente de mecanismos causais que se estabelecem no processo democrático responsivo. A esse respeito ver Powell (2005).

${ }^{5}$ Easton (1975, p.447) já chamara a atenção para esse aspecto ao mencionar que a satisfação com o desempenho do regime representaria a satisfação dos cidadãos não só com os resultados das açóes das autoridades, mas com os próprios processos que levariam a tais resultados. Há, portanto, nessa perspectiva, uma dimensão normativa e difusa na satisfaçáo com o funcionamento do regime, a qual é incluída na presente análise.
} 
diz respeito náo apenas às avaliaçóes de seus resultados e do fato de os serviços públicos serem efetivos, como também às avaliaçôes das práticas democráticas (procedimentos como a justeza, transparência e regularidade das eleiçóes, que garantem a rotatividade democrática do poder, honestidade e probidade dos representantes eleitos e servidores públicos, que fazem parte de modo efetivo da política democrática). Trata-se, portanto, de uma medida avaliativa da democracia, que, baseada em expectativas culturais e racionais dos cidadáos, lida com normas e procedimentos e expressa a frustraçáo quando se compara o que se tem e o que se deveria ter (GUNTHER e MONTERO, 2003; BLAIS e GÉLINEAU, 2007; MOISÉS e CARNEIRO, 2008).

No entanto, não apenas o desempenho do governo e os valores culturais são importantes correlatos da avaliaçáo do sistema democrático e de seus resultados, mas o próprio formato das instituiçóes políticas afeta a satisfação dos indivíduos com o funcionamento da democracia ${ }^{6}$. Isso implica, por exemplo, que os apoiadores do partido no poder verão o funcionamento da democracia em seu país de modo mais positivo do que aqueles cujo partido esteja fora do poder (FUCHS, GUIDOROSSI e SVENSSON, 1995; NORRIS, 1999 e 2011; GUNTHER e MONTERO, 2003; DIAMOND e MORLINO, 2005; BLAIS e GÉLINEAU, 2007).

Todavia, enquanto as eleiçóes democráticas necessariamente produzem perdedores e ganhadores, a democracia baseia-se na premissa de que os perdedores consentem sua perda e aceitam que a democracia trabalha bem, apesar do resultado eleitoral (BLAIS e GÉLINEAU, 2007). De todo modo, embora os governos democráticos devam ser continuamente responsivos às preferências e demandas de seus cidadãos, nas democracias atuais, com tantos e distintos interesses em disputa, a responsividade governamental é fenômeno complexo, e os perdedores ficarão temporariamente insatisfeitos, mas deverão consentir sua perda, na medida em que acreditem que as regras do jogo garantem a rotatividade do poder e permitem que o partido que endossam possa ser eleito em outra ocasiáo. Dessa forma, a satisfação com o funcionamento do regime também deve correlacionar-se com medidas de apoio específico, como a aprovação do Executivo e a preferência partidária, e com as

\footnotetext{
${ }^{6}$ Anderson e Guillory (1997) e Aarts e Thomassen (2008) mostram que diferentes desenhos institucionais do regime democrático, por exemplo, sistemas proporcionais ou majoritários, têm diferentes efeitos sobre a satisfação dos cidadáos com o funcionamento do regime democrático. Essa discussão, no entanto, foge aos objetivos deste artigo.
} 
percepções da capacidade de influência do voto e de representação do sistema (BLAIS e GÉLINEAU, 2007; AARTS e THOMASSEN, 2008).

Essas questóes apontam para a complexidade do fenômeno da satisfação com o funcionamento do regime democrático, que remonta a "um apoio político de nível intermediário, que é frequentemente difícil de captar” (NORRIS, 1999, p. 11; 2011, p. 28). Diante dessa dificuldade estabeleceu-se um debate, ainda não resolvido, sobre a medida clássica ${ }^{7}$ de satisfação com a democracia e sobre o modo de apreender as percepçóes cidadãs acerca do desempenho do regime democrático (CANACHE, MONDAK e SELIGSON, 2001; LINDE e EKMAN, 2003). Quanto à primeira questão, enquanto alguns autores tratam o indicador de satisfaçáo com a democracia como medida de apoio a autoridades (DALTON, 1999), outros a tratam como apoio às normas constitucionais da democracia "em operação", ou avaliação do funcionamento do regime em contraste aos ideais do governo democrático (FUCHS, GUIDOROSSI e SWENSSON, 1995; MOISÉS, 2011). Outros, ainda (FUCHS e KLINGEMANN, 1995; TÓKA, 1995; MISHLER e ROSE, 1999 e 2002), abordam a satisfação com a democracia como equivalente à legitimidade política. Para resumir o debate, usando os termos de Easton (1965 e 1975), as definiçóes sobre o conceito, de um lado, e sobre os usos da medida de satisfaçáo com a democracia, de outro, oscilariam entre o apoio específico e o apoio difuso.

Enquanto a mensuração de quaisquer das dimensões do apoio político não é tarefa fácil, sendo difícil estabelecer distinçôes teóricas finas entre dimensōes e objetos de apoio político com base em itens de surveys, a sobreposição de dimensóes seria particularmente problemática na medida de satisfaçáo com a democracia, uma vez que ela deixa em aberto que critérios ou objetos políticos o respondente deve utilizar para respondê-la (NORRIS, 1999; CANACHE, MONDAK e SELIGSON, 2001). Dessa forma, os indivíduos podem referir-se aos governantes do momento e a seus resultados, a aspectos práticos do regime democrático em oposiçáo a seus princípios ou a um misto dessas dimensóes.

\footnotetext{
7 Trata-se da pergunta "De uma maneira geral, o(a) sr.(a) está muito satisfeito(a), satisfeito(a), pouco(a) satisfeito(a) ou nada satisfeito(a) com o funcionamento da democracia no país?" A pergunta tem sido incluída em diferentes instrumentos de pesquisa de opinião internacionais: Eurobarometer, Latinobarômetro, Comparative Study of Electoral Systems (CSES), Latin American Public Opinion Project (Lapop) e New Democracies Barometer (este último realizado nos países ex-comunistas do Leste Europeu).
} 
Por considerarem a medida de satisfação com a democracia ambígua ${ }^{8}$, Booth e Seligson (2009) utilizam, em seu lugar, indicadores sociotrópicos de avaliaçáo da economia para mensurar as percepçôes sobre o desempenho do regime, justificando que "[...] o desempenho da economia é um fator crítico na avaliação cidadã do governo" (BOOTH e SELIGSON, 2009, p. 43). No entanto, ao restringir o desempenho do regime a seu aspecto econômico, essa perspectiva não leva em conta que os cidadáos também podem estar atentos a aspectos políticos do regime quando respondem à pergunta sobre o funcionamento da democracia. Nesse sentido, McAllister (1999), Montero, Gunther e Torcal (1997), Mishler e Rose (1999, 2001 e 2002) e Bratton e Mattes (2001), analisando cenários distintos, como os países da Europa Ocidental, do Sul e do Leste e da África, têm demonstrado que bens políticos, como as avaliaçóes dos cidadáos sobre as liberdades e os direitos humanos em seus países, podem ser até mais importantes que os bens econômicos na avaliação do desempenho do regime.

Este artigo pretende contribuir para a reunião de subsídios empíricos, a partir do estudo do caso brasileiro, para a análise da proposição teórica de Diamond e Morlino (2005) de que a satisfaçáo com a democracia diz respeito à percepção de responsividade do regime ao articular as dimensóes 'instituiçóes' e 'procedimentos' aos 'resultados' do regime. No plano dos resultados do regime, o intuito é também observar o lugar da dimensão da economia na avaliação do desempenho do regime, face às dimensôes normativas da democracia no cenário brasileiro. Acompanhando as referências que apontam que a satisfação com o desempenho do regime diz respeito a fenômeno multifacetado, a expectativa é de que, embora a dimensão econômica seja importante, o construto do desempenho do regime transcenda sua avaliação. $\mathrm{Na}$ próxima seção, são destacados os resultados do ESEB que são utilizados na discussão da natureza da avaliação do regime democrático, segundo os brasileiros, nesse sentido.

\footnotetext{
${ }^{8}$ Segundo a perspectiva aqui adotada, a base dessa possível ambiguidade, mais do que na forma e medida de mensuração do desempenho do regime, baseia-se na própria definição dessa dimensão do apoio político, que tem sido abordada de modo inespecífico, por exemplo, "satisfação simbólica com os processos pelos quais o país é governado" (EASTON, 1975, p. 447), ou ainda "satisfação com os trabalhos do regime" (NORRIS, 1999, p. 10). Como definir os processos e trabalhos do regime? Para Dalton (2004), que prefere chamar essa dimensão como "normas e procedimentos" (do regime), tratase das avaliaçóes do desempenho do sistema, que podem ser captadas por avaliaçóes de direitos políticos e das normas de participação, além da própria medida de satisfação com o funcionamento da democracia. Essa questão aponta que o próprio conceito de desempenho do regime precisa de estudos adicionais, tema que será abordado em outra etapa da pesquisa que origina este artigo.
} 


\section{O Estudo Eleitoral Brasileiro (ESEB) e questões analisadas}

O ESEB baseia-se em entrevistas individuais face a face, realizadas logo após as eleiçóes presidenciais, e sua primeira onda foi aplicada em 2002. Seus dados permitem explorar de forma longitudinal a evolução da relaçáo dos cidadáos brasileiros com o funcionamento do sistema democrático representativo. As informaçôes básicas das 4 ondas do ESEB estão descritas na Tabela $1^{\text {}}$ :

Tabela 1 - Informaçóes do Estudo Eleitoral Brasileiro (ESEB) ${ }^{10}$

\begin{tabular}{|c|c|c|c|}
\hline Onda & Data das entrevistas & Universo & Tamanho da amostra \\
\hline 2002 & $\begin{array}{l}31 \text { de outubro a } 28 \text { de } \\
\text { dezembro de } 2002\end{array}$ & \multirow{4}{*}{$\begin{array}{c}\text { População brasileira com } 16 \\
\text { anos ou mais }\end{array}$} & 2513 \\
\hline 2006 & $\begin{array}{c}17 \text { a } 27 \text { de dezembro } \\
\text { de } 2006\end{array}$ & & 1000 \\
\hline 2010 & $\begin{array}{l}4 \text { a } 20 \text { de novembro de } \\
2010\end{array}$ & & 2000 \\
\hline 2014 & $\begin{array}{l}1 \text { a } 19 \text { de novembro de } \\
2014\end{array}$ & & 3136 \\
\hline
\end{tabular}

Fonte: ESEB (2002, 2006, 2010 e 2014).

Em países de democracia recente como o Brasil, o apoio político democrático resulta, sobretudo, das experiências institucionais recentes dos indivíduos (EASTON, 1975; MISHLER e ROSE, 2001 e 2002). Nesses cenários, o apoio democrático é, em grande medida, contingente ao desempenho do regime, além da consideração por parte dos cidadáos de seus aspectos normativos. Assim, a avaliaçáo do desempenho da democracia é fenômeno complexo: os cidadãos avaliam não apenas a capacidade de as autoridades proverem os bens econômicos almejados, mas também os resultados de outras políticas públicas, como a segurança, o bem-estar e a igualdade. Avaliam também a accountability e a responsividade dos políticos e instituiçóes (BRATTON e MATTES, 2001; FARAH, BARNES e HEUNKS, 1979; POWELL, 2005). Ainda, a satisfação com a democracia remonta não apenas à avaliação que os cidadãos fazem

\footnotetext{
${ }^{9}$ Com relação à amostragem, as quatro pesquisas são amostras nacionais representativas dos eleitores com 16 anos ou mais, do tipo probabilística estratificada em estágios (municípios, setores censitários e domicílios) e com um último estágio de estratificação segundo cotas dentro dos setores, definidas de acordo com o perfil de idade, escolaridade e população economicamente ativa cruzadas por sexo.

${ }^{10}$ Todas as bases de dados do ESEB estão disponíveis no Banco de Dados de Pesquisa de Opinião do CESOP/UNICAMP.
} 
dos resultados que recebem dos governos e políticas democráticas, como também aos processos políticos que os embasam (EASTON, 1975; NORRIS, 2011).

Cinco conjuntos de questóes foram definidos para analisar o fenômeno da satisfação com a democracia no país: 1. Avaliação de instituiçôes representativas (partidos, congresso, justiça e polícia); 2. Avaliação de serviços e políticas públicas (qualidade da educação e saúde, acesso à justiça, controle da criminalidade, diminuição do desemprego e diminuição das desigualdades sociais); 3. Avaliação retrospectiva da gestão da economia; 4. Avaliação dos governantes do momento (incumbentes políticos); e 5. Percepçóes normativas da democracia - preferência democrática em comparação a outros regimes, percepção do voto como mecanismo de influência no sistema político democrático (proxy de norma de accountability vertical, seguindo Arts e Thomassen (2008)) e sentimento de representação pelo sistema (ter identificação partidária) ${ }^{11}$.

A distribuição das respostas positivas para o período entre 2002 e 2010 (Tabelas 2 e 3) mostra a convivência da crítica às instituiçôes representativas e aos resultados de políticas públicas e das percepçóes positivas sobre a democracia em termos normativos, reiterando cenários paradoxais já relatados desde o início da experiência democrática brasileira recente (MOISÉS, 1995 e 2010a; BAQUERO, 1994 e 2012) e comum a outros países de democracia recente e longamente estabelecida (BOOTH e SELIGSON, 2009; NORRIS, 1999 e 2011). Dessa forma, no que diz respeito às percepçóes normativas da democracia, os dados da Tabela 2 mostram que, mesmo com a queda na preferência pela democracia em 2014, a crença na legitimidade democrática é elevada. Ao seu lado, a percepção do voto como mecanismo que exerce influência no que acontece no país também é majoritária no período. Na leitura desses dados, há que se considerar os efeitos dos momentos de realização das pesquisas: conjunturas eleitorais têm efeitos politizadores que podem influenciar positivamente a percepção dos mecanismos democráticos (MOISÉS, 1995; BLAIS e GÉLINEAU, 2007; ROSE, 2007). Por outro lado, não mais do que $40 \%$, declaram que algum partido representa seu modo de pensar em todo o período (percentual que oscila para baixo em 2006 e 2014).

\footnotetext{
${ }^{11} \mathrm{Na}$ ausência de um indicador melhor de percepção da representação pelo regime democrático, como já apontado na nota 9 deste artigo, a pergunta "Existe algum partido que representa a maneira como $o$ senhor pensa?", presente em todas as ondas do ESEB, é utilizada como medida de sentimento de representação pelo sistema. Trata-se de indicador imperfeito, mas é a informação disponível no conjunto dos dados que mais se aproxima da percepçáo de representatividade do regime.
} 
O cenário também é menos positivo quando se olha para as avaliaçóes do congresso, dos partidos e da justiça: em todo o período, as somas das avaliaçóes positivas são bastante modestas e apresentam, inclusive, uma trajetória descendente. Por último, a satisfação com a democracia, dimensão avaliativa do apoio político, ainda que esteja bastante aquém da preferência pelo regime democrático, segue uma trajetória similar a esta enquanto tendência entre 2002 e 2014 - aumento entre 2002 e 2010 e queda em 2014 (Tabela 2):

Tabela 2 - Variáveis de percepção normativa da democracia e avaliação do desempenho do regime (\%)

\begin{tabular}{|c|c|c|c|c|c|}
\hline Variáveis & & 2002 & 2006 & 2010 & 2014 \\
\hline $\begin{array}{l}\text { Voto influencia o que acontece } \\
\text { no Brasil }\end{array}$ & $\begin{array}{l}\text { (soma dos graus influencia } \\
\text { muito e influencia) }\end{array}$ & 78,8 & 77,6 & 83,9 & 79,6 \\
\hline $\begin{array}{l}\text { Algum partido representa a } \\
\text { maneira como o eleitor pensa }\end{array}$ & $(\operatorname{sim})$ & 40,7 & 29,4 & 40,4 & 28,1 \\
\hline \multicolumn{2}{|c|}{$\begin{array}{l}\text { A democracia é sempre melhor do que qualquer outra forma de } \\
\text { regime }\end{array}$} & 69,3 & 77,2 & 85,4 & 77,9 \\
\hline $\begin{array}{l}\text { Satisfaçáo com o funcionamento } \\
\text { da democracia no país }\end{array}$ & $\begin{array}{l}\text { (muito satisfeito + } \\
\text { satisfeito) }\end{array}$ & 30,7 & 44,7 & 50,2 & 40,7 \\
\hline Avaliaçáo do governo/presidente & (bom + muito bom) & 41,0 & 76,2 & 93,9 & 45,9 \\
\hline Avaliação Congresso & \multirow{4}{*}{ (ótima + boa) } & 40,4 & 27,0 & 25,3 & 16,8 \\
\hline Avaliação Partidos & & 37,3 & 26,5 & 20,9 & 15,5 \\
\hline Avaliação Justiça & & 42,4 & 41,3 & 29,5 & 23,7 \\
\hline Avaliação Polícia & & 52,5 & 51,7 & 33,4 & 25,7 \\
\hline
\end{tabular}

Obs: somente respostas válidas.

Fonte: ESEB (2002, 2006, 2010 e 2014).

Os dados para o ESEB 2010 e 2014 permitem visualizar ainda as percepçóes de alguns resultados do regime democrático (Tabela 3). Com relação à avaliação da economia, enquanto em 2010 mais da metade dos entrevistados viam a situação econômica do país como melhor do que a de 2009, em 2014, apenas 24,7\% acreditavam que ela estivesse melhor em comparaçáo ao ano anterior ${ }^{12}$. $\mathrm{O}$ cenário

\footnotetext{
12 Apenas a título de referência, no ESEB 2010, 56,2\% dos entrevistados avaliavam a situação econômica do país como 'boa' ou 'ótima' e 28,6\% a avaliavam como 'regular'. Em torno de $80 \%$ avaliavam, então, a economia de modo positivo ou regular. Infelizmente, para os ESEB 2014, não há a variável de avaliação da situação econômica do momento para dimensionar de quanto foi, de fato, a
} 
também aponta para a insatisfação acentuada dos cidadãos com relação a políticas e serviços públicos. A quantidade de notas 7 a 10 para todos esses serviços são minoritárias e, ademais, decrescentes no período:

Tabela 3 - Satisfação com a situação econômica e com políticas públicas (\%)

\begin{tabular}{|c|c|c|c|}
\hline Variáveis & & 2010 & 2014 \\
\hline $\begin{array}{l}\text { Situação econômica em comparação aos } 12 \text { meses } \\
\text { anteriores }\end{array}$ & (melhor) & 55,1 & 24,7 \\
\hline Controle da criminalidade & \multirow{6}{*}{$\begin{array}{c}\text { (soma das respostas } \\
\text { de } 7 \text { a } 10, \text { onde } 10= \\
\text { "totalmente } \\
\text { satisfeito") }\end{array}$} & 6,8 & 5,4 \\
\hline Diminuição das desigualdades sociais & & 14,5 & 9,7 \\
\hline Acesso do cidadão comum à justiça & & 17,8 & 10,5 \\
\hline Qualidade do ensino público & & 26,0 & 15,4 \\
\hline Acesso aos serviços de atendimento médico & & 12,5 & 8,1 \\
\hline Diminuição do desemprego & & 23,9 & 12,8 \\
\hline
\end{tabular}

Obs: somente respostas válidas.

Fonte: ESEB (2002, 2006, 2010 e 2014).

Com o intuito de avançar na compreensão de quais dimensões mais se relacionam à satisfação com o funcionamento do regime democrático, os dados para 2010 e 2014 foram selecionados para os procedimentos estatísticos apresentados na sequência.

Em trabalho anterior, com base nesses mesmos dados (DEL PORTO, 2016), a execução de técnicas de análise de componentes principais mostrou que a dimensão da legitimidade democrática (apoio normativo e voto) articula-se às avaliaçóes dos resultados do regime $\mathrm{e}$ de suas autoridades e instituiçóes no construto multidimensional de avaliação do funcionamento da democracia no Brasil. Embora esses resultados ainda necessitem de testes adicionais, em seu conjunto, eles sugeriram que aspectos normativos do regime importam para essa avaliaçáo, confirmando achados de Aarts e Thomassen (2008) para outros contextos.

Trata-se, aqui, ainda de modo descritivo, de explorar os fatores que fomentam a satisfação com a democracia no país no cenário recente. Qual o impacto da percepção da efetividade das normas do regime sobre a satisfação com a democracia em comparação aos efeitos de seus resultados? Características demográficas, socioeconômicas e culturais dos indivíduos (sexo, cor, idade, regiáo e escolaridade,

piora na avaliação da situação econômica “atual” em 2014 comparativamente a 2010, segundo os entrevistados. 
hábito de leitura de jornais e assistência a telejornais com notícias nacionais) correlacionam-se à percepçáo do desempenho da democracia brasileira?

Para tratar dessas questóes, foram realizados modelos de regressão logística, tendo sido a satisfação com a democracia caracterizada como variável dependente binomial ${ }^{13}$. As variáveis independentes também foram definidas como dicotômicas - a codificação das variáveis está no Anexo -, possibilitando uma comparação direta dos seus efeitos sobre a satisfação com democracia. A Tabela 4 apresenta as razóes de chance (coeficientes OR- $\operatorname{Exp}(B))$ de ocorrência da satisfação com o funcionamento da democracia segundo os modelos especificados:

\footnotetext{
${ }^{13}$ A satisfação com a democracia é mensurada através da pergunta: "De uma maneira geral, o(a) $\operatorname{sr}(a)$ está muito satisfeito(a), satisfeito(a), pouco satisfeito(a) ou não está satisfeito (a) com o funcionamento da democracia no Brasil?". A variável foi tratada como dicotômica: satisfeitos (soma das respostas "muito satisfeito" e "satisfeito") e náo satisfeitos (soma das respostas "pouco satisfeitos" e "nada satisfeitos"). As respostas "nem satisfeito nem insatisfeito", "não sabe" e "não respondeu” foram incluídas na categoria "não satisfeitos"). As análises foram então realizadas em relação à categoria "satisfeitos" com o funcionamento do regime.
} 
Tabela 4 - Preditores da Satisfação com o Funcionamento da Democracia

\begin{tabular}{|c|c|c|}
\hline Variáveis independentes & 2010 & 2014 \\
\hline Avaliação do governo/presidente & $2,514^{* *}$ & $2,007^{* *}$ \\
\hline Avaliação da economia comparada aos 12 meses anteriores & ,771 & $2,347^{* *}$ \\
\hline Avaliação do Congresso Nacional & 1,181 & ,912 \\
\hline Avaliação dos Partidos Políticos & 1,250 & $1,435^{*}$ \\
\hline Avaliação do Poder Judiciário & 1,067 & $1,870^{* *}$ \\
\hline Avaliaçáo da Polícia & 1,237 & 1,004 \\
\hline Satisfação com redução da criminalidade & ,930 &, $723^{*}$ \\
\hline Satisfação com redução das desigualdades sociais & ,674** & ,822 \\
\hline Satisfação com acesso do cidadão comum à justiça & 934 & 1,024 \\
\hline Satisfação com diminuição do desemprego & 1,044 & 1,026 \\
\hline Satisfação com serviço de saúde pública & 1,046 & ,759 \\
\hline Satisfação com serviço de educação pública & ,619** & ,959 \\
\hline Sentimento de representação por partido político & $1,529^{* *}$ & $1,652^{* *}$ \\
\hline Percepção de influência do voto & $1,359^{*}$ & 1,122 \\
\hline Prefere a democracia & $3,257^{* *}$ & $1,562^{* *}$ \\
\hline Costuma ler jornais & ,813 & ,868 \\
\hline Assistiu telejornais com notícias nacionais na semana & 1,354 & 1,259 \\
\hline Escolaridade &, 838 & 1,035 \\
\hline Idade &, $702^{*}$ & 1,062 \\
\hline Sexo & $1,595^{* *}$ & 1,125 \\
\hline Cor & 1,115 & 1,195 \\
\hline Região & ,658 & 1,029 \\
\hline $\mathrm{R}^{2}$ Nagelkerke & 203 & , 189 \\
\hline $\mathrm{N}$ & 1091 & 2521 \\
\hline
\end{tabular}

${ }^{*}$ sig. a, $01{ }^{* *}$ sig. a, 05 .

Variável dependente: satisfação com o funcionamento da democracia no país.

Nota: Nos 2 anos, os números das amostras dos modelos são menores do que os totais das amostras (Tabela 1) devido aos missing cases contidos na variável dependente.

Fonte: Elaboração própria a partir do ESEB (2010 e 2014). 
Nos dois anos, a avaliação dos governos aparece como o principal correlato da satisfação com a democracia, apontando para o papel dos fatores de curto prazo, ou apoio específico, sobre ela ${ }^{14}$. $\mathrm{O}$ apoio normativo ao regime democrático, assim como ter uma identificação partidária, variáveis de longo prazo ou apoio difuso, também aumentam de modo expressivo as chances de satisfação com a democracia nos dois anos.

Para além dessas três variáveis, as demais variáveis de avaliaçáo das instituições, das políticas, da situação econômica e do voto têm efeitos menos expressivos, e em apenas um ou outro dos anos - demonstrando efeitos contextuais sobre a satisfação com a democracia no país. Nesse terreno, o primeiro resultado que deve ser destacado diz respeito à avaliação retrospectiva da situação econômica, que, embora em 2014 tenha apresentado o mais forte efeito sobre a satisfação com a democracia, não havia alcançado impacto significativo em 2010. Embora esse resultado ainda demande testes adicionais, isso sugere que nem sempre a dimensão econômica explica a avaliação que os cidadãos fazem do funcionamento do regime democrático. Pode-se supor, nesse caso, que a percepção da economia seja significativa para a avaliação da democracia em momentos de conjunturas mais desfavoráveis. Ademais, como, em 2010, a avaliação da gestão do presidente Lula era extremamente positiva, ela pode ter concentrado os efeitos positivos sobre a satisfaçáo com a democracia. Os dados aqui utilizados não permitem, no entanto, avançar a discussão nesse sentido.

Os efeitos de alguns resultados do regime sobre a satisfaçáo com seu funcionamento também parecem variar de acordo com as conjunturas: no âmbito das políticas públicas, enquanto, em 2010, as avaliações da diminuição das desigualdades sociais e da qualidade da educação pública impactaram a satisfação com a democracia, em 2014, sobressai o efeito da percepção de diminuição da criminalidade sobre a satisfação com a democracia. As eventuais diferenças na conjuntura econômica e

\footnotetext{
${ }^{14}$ Embora avaliação do governo/presidente e satisfaçáo com o funcionamento do regime refiram-se a construtos distintos, poderia haver alguma colinearidade entre os dois indicadores (as correlaçóes entre ambos, medidas pelo "kendall's tau-b" e "spearman", foram, respectivamente: para $2010=, 209$ e ,233; para 2014=,264 e ,309 (todas com nível de significância de ,01)). No entanto, a retirada da variável "avaliaçáo do governo" dos modelos para os 2 anos náo alterou significativamente a capacidade explicativa dos mesmos. Diante disso, e dada a relevância analítica desse construto, ele foi mantido nas análises aqui apresentadas. A distinção entre satisfação com a democracia e a avaliação dos governos do momento é uma discussão importante aos estudos de apoio político no cenário brasileiro, a qual será abordada em outra etapa da pesquisa, referenciada na nota 1 deste artigo.
} 
social do país entre os dois momentos, mais positiva em 2010 do que em 2014, podem ter contribuído para esses resultados.

No que se refere à percepção dos mecanismos e instituiçóes da democracia representativa, os resultados são mistos: por um lado, quanto às instituiçôes, chama a atenção o fato de que, em 2010, a avaliação de nenhuma das instituiçóes afete a satisfação com a democracia no país. Em 2014, por sua vez, avaliar positivamente os partidos políticos e a justiça aumentam a satisfação com o desempenho do regime. Os efeitos apenas pontuais tanto da avaliaçáo de instituiçóes como de serviços sobre a satisfação com o funcionamento da democracia no país adicionam evidências às consideraçóes de Meneguello (2010) de que, no mapa dos cidadáos brasileiros, a satisfação com o funcionamento do regime não está articulada diretamente às avaliaçôes de instituiçôes e de serviços públicos. Os modelos aqui definidos para 2010 e 2014, aliás, com capacidade explicativa de cerca de $20 \%$ da satisfação com a democracia no Brasil, sugerem que o fenômeno é, de fato, mais complexo do que as dimensôes possíveis de serem definidas com base nos dados aqui utilizados.

Ainda com relação aos mecanismos democráticos, chama atenção que, em 2014, aqueles que acreditam no voto como mecanismo de accountability vertical não estão mais satisfeitos com o funcionamento da democracia no país. Esse resultado, em desacordo com as expectativas teóricas, pode dever-se ao contexto da eleição presidencial de 2014, a mais disputada no período democrático recente ${ }^{15}$, mas ainda são necessárias novas análises para melhor qualificar esse cenário.

Foi notável que a satisfação com o funcionamento da democracia não tenha se associado à escolaridade nem aos hábitos de ler jornais ou assistir a telejornais com notícias nacionais, o que também contraria a expectativa de que os mais mobilizados cognitivamente mostrar-se-iam mais insatisfeitos e críticos com o funcionamento do regime (NORRIS, 2011).

Com relação ao impacto das variáveis sociodemográficas, apenas no primeiro desses anos, os mais jovens e as mulheres mostravam menos chances de estarem satisfeitos com o funcionamento da democracia, resultados que, associados aos efeitos também negativos das avaliaçôes das políticas de redução da desigualdade e qualidade do ensino público, sugerem que jovens e mulheres estavam menos satisfeitos com essa gestão do cotidiano naquele momento. Fora esse resultado, o impacto das variáveis socioeconômicas e demográficas sobre a satisfação com a democracia é quase nulo nos dados aqui explorados. Esse resultado, de todo modo, não deixa de ser significativo,

\footnotetext{
${ }^{15}$ Uma análise deste pleito pode ser encontrada em Amaral e Ribeiro (2015).
} 
tendo em vista que, no início do período democrático recente, desigualdades socioeconômicas e culturais colocavam as mulheres, os mais jovens, os menos escolarizados, os mais marginalizados e excluídos como mais satisfeitos com a democracia "realmente existente", embora menos aderidos a ela em termos normativos (MOISÉS, 1995).

\section{Considerações finais}

No cenário latino-americano recente, Seligson e Smith (2010) apontam para os efeitos da percepção da crise econômica sobre os valores democráticos, entre os quais a satisfação com a democracia. Os resultados dos autores apontam que, mais do que a percepção da gravidade da crise, os cidadáos estáo atentos e avaliam o modo como essa é gerida pelos governantes do momento, e essa percepção tem impacto importante sobre o nível de satisfação com a democracia.

Em certo sentido, os resultados do ESEB aqui explorados também parecem apontar nessa direção: enquanto, em 2010, a visão positiva retrospectiva da economia não esteve entre os correlatos da satisfação com a democracia, em 2014, ela emerge como o mais importante fator para explicar a avaliação do regime. Na leitura desses resultados, há que se considerar a diferença dos cenários econômicos dos dois momentos: mesmo que, em 2014, o país ainda não atravessasse uma crise política e econômica como a iniciada em 2015, a percepçáo do cenário já era bem menos positiva do que em 2010, tanto em termos econômicos e sociais como em relação à avaliação de seus governantes. Nos dois anos, de todo modo, as avaliaçóes dos executivos federais são centrais para explicar quão satisfeitos os cidadãos estáo com a democracia. Ou seja, tal como nos resultados relatados por Seligson e Smith (2010), as percepçóes que os cidadãos têm sobre o modo como as autoridades dirigem o país e lidam com a diversidade de questôes percebidas como socialmente prioritárias, entre as quais a gestáo da economia e da crise, estão no âmago da avaliação do desempenho do regime democrático.

Por outro lado, tendo em vista os resultados de Meneguello (2010), que apontaram para a dissociação entre a avaliação das instituiçóes representativas e a satisfação com a democracia, o artigo buscou explorar os efeitos das primeiras como mecanismos que fazem a intermediação dos cidadãos com o regime democrático sobre a satisfaçáo com o seu funcionamento. Ao seguir nessa direção, este estudo incorporou um aspecto ainda não mensurado nas análises sobre o desempenho do regime democrático no país, qual seja, a percepção sobre a dimensão normativa da 
democracia representativa. Tendo em vista a experiência recente dos brasileiros com a democracia, explorar essa relação parece fundamental. Os resultados, embora ainda exploratórios, sugerem que medidas de apoio normativo à democracia adicionam capacidade explicativa à satisfação com o regime democrático. Nesta, além do apoio ao regime, chama atençáo que ter uma identidade partidária esteja entre os fatores institucionais que mais se correlacionem com a chance de satisfação com a democracia através do tempo, o que deve ser explorado em estudos posteriores à luz das teorias da democracia representativa.

Finalmente, sem negar a importância da gestão econômica sobre a avaliação do desempenho da democracia, este artigo acompanha os estudos que apontam que a percepção do funcionamento da democracia é mais complexa.

- Fabíola Brigante Del Porto é Doutora em Ciência Politica pela Universidade Estadual de Campinas e Pesquisadora do Centro de Estudos de Opinião Pública (CESOP) da Universidade Estadual de Campinas (UNICAMP). E-mail: delporto@unicamp.br.

\section{Referências}

AARTS, Kees; THOMASSEN, Jacques. Satisfaction with democracy: do institutions matter? Electoral Studies, 27, p. 5-18, 2008.

AMARAL, Oswaldo; RIBEIRO, Pedro Floriano. Por que Dilma de novo? Uma análise exploratória do Estudo Eleitoral Brasileiro de 2014. Revista de Sociologia e Política, v. 23, n. 56, dez. 2015. Disponível em <http://www.scielo.br/scielo.php?script=sci_arttext\&pid=S010444782015000400107\&lng=pt\&nrm=iso >. Acesso em 04 ago. 2016.

ANDERSON, Cristopher; GUILLORY, Christine. A. Political institutions and satisfaction with democracy: a cross-national analysis of consensus and majoritarian systems. American Political Science Review, v. 91, n. 1, p. 66-82, 1997.

BAQUERO, Marcello. Os desafios na construção de uma cultura política democrática na América Latina: estado e partidos políticos. In: Baquero, Marcello (Org). Cultura política e democracia - os desafios das sociedades contemporâneas. Porto Alegre, UFRGS, 1994.

. Memória política e constituição da cultura política brasileira. Ciências Sociais Unisinos, v. 48, p. 84-92, 2012.

BLAIS, André; GÉLINEAU, François. Wining, losing and satisfaction with democracy. Political Studies, v. 55, p. 425-441, 2007. 
BOBBIO, Norberto. O futuro da democracia: uma defesa das regras do jogo. Rio de Janeiro: Paz e Terra, 1986.

BOOTH, John; SELIGSON, Mitchell. The legitimacy puzzle in Latin America: political support and democracy in eight nations. Cambridge University Press, 2009.

BRATTON, Michael; MATTES, Robert. Support for democracy in Africa: intrinsic or instrumental? British Journal of Political Science, v. 31, v. 3, p. 447-474, 2001.

CANACHE, Damaris; MONDAK, Jeffrey; SELIGSON, Mitchell. Meaning and measurement in cross-national research on satisfaction with democracy. Public Opinion Quarterly, v. 65, p. 506-528, 2001.

CESOP. Banco de Dados de Pesquisas de Opinião do Centro de Estudos de Opinião Pública. Disponível em <http://www.cesop.unicamp.br/busca/CESOP/pesquisa_usuario >. Acesso em 30 mar. 2016.

DAHL, Robert. Poliarquia. São Paulo: EdUsp, 1997.

DALTON, Russell. Political support in advanced industrial democracies. In: NORRIS, Pippa. (org.). Critical citizens: global support for democratic governance. Oxford: Oxford University Press, 1999.

- Democratic challenges, democratic choices: the erosion of political support in advanced industrial democracies. Oxford: Oxford University Press, 2004.

DEL PORTO, Fabíola. O que explica a (in)satisfação com a democracia entre os brasileiros no cenário recente? Trabalho apresentado no XXXIV Congresso Internacional da LASA. New York, New York, 27 a 30 de maio de 2016.

DIAMOND, Larry; MORLINO, Leonardo. Assessing the quality of democracy. Baltimore: The Johns Hopkins University Press, 2005.

EASTON, David. A system analysis of political life. New York: Willey Press, 1965.

. A re-assessment of the concept of political support. British Journal of Political Science, v. 5, n. 4, 1975.

ESEB 2002 - Estudo Eleitoral Brasileiro. CESOP/FGV. In: Banco de Dados do Centro de Estudos de Opinião Pública - CESOP - UNICAMP. No CESOP/FGV/BRASIL02.DEZ-01838. Disponível em <http://www.cesop.unicamp.br/busca/CESOP/pesquisa_usuario >. Acesso em 30 mar. 2016.

ESEB 2006 - Estudo Eleitoral Brasileiro. CESOP/IPSOS. In: Banco de Dados do Centro de Estudos de Opinião Pública - CESOP - UNICAMP. No CESOP/IPSOS/BRASIL06.DEZ-02849.

Disponível em <http://www.cesop.unicamp.br/busca/CESOP/pesquisa_usuario>. Acesso em 30 mar. 2016.

ESEB 2010 - Estudo Eleitoral Brasileiro. CESOP/VOX POPULI. In: Banco de Dados do Centro de Estudos de Opinião Pública - CESOP - UNICAMP. No CESOP/VOXPOPULI/BRASIL10.NOV02639. Disponível em <http://www.cesop.unicamp.br/busca/CESOP/pesquisa_usuario $>$. Acesso em 30 mar. 2016.

ESEB 2014 - Estudo Eleitoral Brasileiro. CESOP/IBOPE. In: Banco de Dados do Centro de Estudos de Opinião Pública - CESOP - UNICAMP. No CESOP/IBOPE/BRASIL14.NOV-03928.

Disponível em <http://www.cesop.unicamp.br/busca/CESOP/pesquisa_usuario $>$. Acesso em 30 mar. 2016. 
FARAH, Barbara; BARNES, Samuel; HEUNKS, Felix. Political dissatisfaction. In: BARNES, S.; KAASE, M. Political action: mass participation in five western democracies. Beverly Hills, CA: Sage, 1979.

FUCHS, Dieter; GUIDOROSSI, Giovanna; SVENSSON, Palle. Support for the democratic system. In: KLINGEMANN, H.-D.; FUCHS, D. (org.). Citizens and the State. Cambridge University Press, 1995.

FUCHS, Dieter; KLINGEMANN, Hans-Dieter. Citizens and the State: a relationship transformed. In: KLINGEMANN, Hans-Dieter; FUCHS, Dieter (org.). Citizens and the State. Cambridge University Press, 1995.

GUNTHER, Richard; MONTERO, José Ramon. Legitimidade democrática em novas democracias. Opiniáo Pública, v. IX, n. 1, 2003.

KLINGEMANN, Hans-Dieter. Mapping political support in the 1990s: a global analysis. In: NORRIS, Pippa (org.). Critical citizens: global support for democratic governance. Oxford: Oxford University Press, 1999.

LINDE, Jonas; EKMAN, Joakim. Satisfaction with democracy: a note on a frequently used indicator in comparative politics. European Journal of Political Research, v. 42, p. 391-408, 2003.

MCALLISTER, Ian. The economic performance of governments. In: NORRIS, Pippa (org.). Critical citizens: global support for democratic governance. Oxford: Oxford University Press, 1999.

MENEGUELLO, Rachel. Aspectos do desempenho democrático: estudo sobre a adesão à democracia e avaliação do regime. In: MOISÉS, José Álvaro (org.). Democracia e confiança. Por que os cidadãos desconfiam das instituiçóes públicas? São Paulo: EdUsp, 2010.

As bases do apoio ao regime democrático no Brasil. In: MOISÉS, José Álvaro; MENEGUELLO, Rachel (orgs.). A desconfiança politica e os seus impactos na qualidade da democracia. São Paulo: EdUsp, 2013.

MISHLER, William; ROSE, Richard. Five years after the fall: trajectories of support for democracy in post-communist Europe. In: NORRIS, Pippa (org.). Critical citizens: global support for democratic governance. Oxford: Oxford University Press, 1999.

What are the origins of political trust? Testing Institutional and Cultural theories in PostCommunist Societies. Comparative Political Studies, v. 34, n. 1, 2001.

Learning and re-learning regime support: the dynamics of post-communist regimes. European Journal of Political Research, v. 41, n. 1, 2002.

MOISÉS, José Álvaro. Os brasileiros e a democracia: bases sócio-políticas da legitimidade democrática. São Paulo: Editora Ática.

. A desconfiança nas instituições democráticas. Opiniáo Pública, v. XI, n. 1, 2005.

Cultura política, instituiçôes e democracia: liçôes da experiência brasileira. In: (org.).

Democracia e confiança. Por que os cidadãos desconfiam das instituiçóes públicas? São Paulo: EdUsp, 2010a.

(org.). Democracia e confiança. Por que os cidadãos desconfiam das instituiçóes públicas? São Paulo: EdUsp, 2010b.

MOISÉS, José Álvaro; CARNEIRO, Gabriela. Democracia, desconfiança política e insatisfação com o regime: o caso do Brasil. Opiniáo Pública, v. 14, n. 1, jun.2008.

MOISÉS, José Álvaro; MENEGUELLO, Rachel (orgs.). A desconfiança politica e os seus impactos na qualidade da democracia. São Paulo: EdUsp, 2013. 
MONTERO, José Ramon; GUNTHER, Richard; TORCAL, Mariano. Actitudes hacía la democracia en España: legitimidad, descontento y desafección. Revista Española de Investigaciones Sociológicas, v. 83, Sept. 1998.

NORRIS, Pippa (org.). Critical citizens: global support for democratic governance. Oxford: Oxford University Press, 1999.

. Democratic Deficit: critical citizens revisited. Cambridge University Press, 2011.

O’DONNELL, Guillermo. Democracia, agência e estado: teoria com intenção comparativa. Sáo Paulo: Paz e Terra, 2011.

POWELL, G. Bingham. The chain of responsiveness. In: DIAMOND, L.; MORLINO, L. (eds.). Assessing the quality of democracy. Baltimore: The Johns Hopkins University Press, 2005.

RENNÓ, Lucio. et al. Legitimidade e qualidade da democracia no Brasil: uma visão da cidadania. São Paulo: Intermeios; Nashville: LAPOP, 2011.

ROSE, Richard. Perspectives on political behavior on time and space. In: DALTON, Russell; KLINGEMANN, Hans-Dieter (eds.). The Oxford Handbook of Political Science. New York: Oxford University Press, 2007.

SARSFIELD, Rodolfo; ECHEGARAY, Fabián. Opening the black box: how satisfaction with democracy and its perceived efficacy affect regime preference in Latin America. International Journal of Public Opinion Research, v. 18, n. 2, 2005. p. 153-173.

SELIGSON, Mitchell; SMITH, Amy. Erica. The political culture of democracy, 2010. Democratic consolidation in the Americas in hard times. Vanderbilt University, 2010.

SCHUMPETER, Joseph. Capitalismo, socialismo e democracia. Rio de Janeiro: Zahar, 1984.

TÓKA, Gábor. Political support in East-Central Europe. In: KLINGEMANN, Hans-Dieter; FUCHS, Dieter (org.). Citizens and the State. Cambridge University Press, 1995.

Texto recebido em 15 de setembro de 2016. Aprovado em 15 de novembro de 2016. 


\section{Anexo}

\section{Definição das variáveis independentes utilizadas nas análises de regressões logísticas}

Todas as variáveis independentes foram recodificadas como categóricas binárias (dummies), conforme descrição abaixo:

1. Avaliação do Governo/Executivo Federal

Na sua opinião, de uma maneira geral o Governo XXX nos últimos 4 anos foi muito bom, bom, ruim ou péssimo?

As respostas foram recodificadas nas respostas 'avaliação positiva'(muito bom, bom) e 'avaliaçáo negativa' (ruim, péssima). A resposta 'regular' (espontânea) foi considerada como positiva.

2. Avaliação das instituiçôes representativas

Para os três anos a variável é: Eu vou falar o nome de várias instituiçóes e gostaria que o senhor dissesse se avalia a atuaçâo de cada uma como ótima, boa, ruim ou péssima? (Instituiçôes utilizadas na análise: Polícia; Justiça; Partidos politicos; Congresso).

As respostas foram recodificadas nas respostas 'avaliação positiva'(muito bom, bom) e 'avaliação negativa' (ruim, péssima). A resposta 'regular' (espontânea) foi considerada como positiva.

3. Avaliação de políticas e serviços públicos

Vou citar algumas politicas e gostaria que o sr. dissesse o quanto está satisfeito com cada uma delas.(Politicas utilizadas na análise: "Controle da criminalidade"; "Diminuição das desigualdades sociais"; "Acesso do cidadão comum à justiça"; "Qualidade do ensino público"; "Acesso aos serviços de atendimento médico"; "Diminuição do desemprego". As respostas foram assim recodificadas: notas 0 a 4 - avaliação negativa e notas 5 a 10 - avaliaçáo regular/ positiva.

4. Percepção da accountability vertical Algumas pessoas dizem que o nosso voto influencia muito no que acontece no Brasil, outras dizem que o nosso voto NÄO influencia nada no que acontece no Brasil. Gostaria que o senhor desse uma nota de 1 a 5. 
Em 2010, o 1 significa que o nosso voto influencia muito, e o 5 significa que o nosso voto NÄO influencia nada no que acontece no Brasil. O que o senhor acha? Os graus 1 e 2 foram recodificados na resposta 'influencia' e os graus 3 a 5 como 'mais ou menos ou não influencia'.

Em 2014, o 1 significa que o nosso voto NÂO influencia nada no que acontece no Brasil e 5 significa que o voto influencia muito no que acontece no Brasil. O que o senhor acha?

Os graus 1 a 3 foram recodificados na resposta 'mais ou menos ou não influencia' e os graus 4 e 5 como 'influencia'.

5. Apoio normativo à democracia

Na sua opinião: 1.A democracia é sempre melhor que qualquer outra forma de governo; OU 2.Em algumas situaçóes é melhor uma ditadura do que uma democracia.

As categorias de resposta incluem ainda a opção espontânea "Tanto faz / Nenhuma das duas é melhor". As respostas foram recodificadas em: 'prefere democracia' e 'outras respostas' (incluindo Ditadura, Tanto faz, Não sabe e Não respondeu).

6. Representação por partidos Existe algum partido que representa a maneira como o senhor pensa? Variável original dicotômica: 'sim' e 'não'.

7. Avaliação da situação econômica do país

O sr. considera que a situação econômica atual do país está melhor, igual ou pior que há 12 meses? As respostas foram recodificadas em: 'melhor' $\mathrm{e}$ 'igual/pior.'

8. Grau de instrução

Variável categorizada em diferentes níveis nos vários anos foi recodificada em: 'Baixa/média escolaridade'=até Ensino Médio incompleto e 'Elevada escolaridade' $=$ pelo menos Ensino Médio completo. 
9. Faixa etária

A variável original 'idade' (contínua) foi categorizada em dois grupos: 'até 29 anos (inclusive)' e '30 anos ou mais'.

10. Região

Variável original REGIÃO categórica com 5 categorias de resposta - Norte,. Nordeste, Centro-Oeste, Sudeste e Sul - foi dicotomizada em 'Regiāo sudeste' e 'Outras'.

11. Cor

Variável original COR categórica com 5 categorias de resposta - Branco, Preto, Pardo/Moreno, Amarelo, Indigena - foi dicotomizada em 'Branco' e 'Não branco'. 